\title{
Editorial
}

\section{The Second Annual Meeting of the Brazilian Institute of Neuropsychology and Behavior (IBNeC)}

\author{
Izabel Hazin ${ }^{1}$, Maria Lucia Simas ${ }^{2}$ \\ 1 - Universidade Federal do Rio Grande do Norte, RN, Brazil \\ 2 - Universidade Federal de Pernambuco, PE, Brazil
}

Instituto Brasileiro de Neuropsicologia e Comportamento (IBNeC; Brazilian Institute of Neuropsychology and Development) convened its second annual meeting in Recife (PE) on October 1315,2011 . IBNeC was founded in 2006 with the aim of integrating psychology and neuroscience domains and representing neuropsychologists and neuroscientists interested in diverse sectors of scientific endeavor. This second annual IBNeC meeting successfully brought together researchers, professionals, and students in psychology and related areas from all regions of Brazil to discuss different research domains in neurosciences and their links with psychology.

Neuroscience and Cognitive Psychology, together with Artificial Intelligence, Philosophy, Anthropology, and Linguistics, took part in the emergence of the so-called Cognitive Revolution. This theoretical movement was centrally founded based on the principle of interdisciplinarity as a common and necessary platform for building a better understanding of the organization and structure of the brain and its relationship with superior human psychological processes. In accordance with the central propositions of cognitive sciences, the scientific program of the second annual meeting of IBNeC was formulated to allow interdisciplinary debate among basic research areas including discussions of conceptual and epistemological questions and aspects related to teaching and the professional development of psychologists and neuropsychologists in Brazil. More

Izabel Hazin, Programa de Pós-Graduação em Psicologia da Universidade Federal do Rio Grande do Norte - UFRN. Maria Lucia Simas, Laboratório de Percepção Visual, LABVIS-UFPE, Departamento de Psicologia, Universidade Federal de Pernambuco, UFPE, Recife, PE, Brasil. Correspondence regarding this article should be directed to: Izabel Hazin, Programa de Pós-Graduação em Psicologia da Universidade Federal do Rio Grande do Norte - UFRN. Av. Sen. Salgado Filho, 3000 - Lagoa Nova - Natal - RN, Brazil - 59078-970, Phone: (84) 3215-3119. E-mail izabel.hazin@gmail.com. than 500 participants shared this central target during the second annual meeting of the $\mathrm{IBNeC}$, contributing to the analysis of teaching and research policies, presenting research data, and exchanging ideas on the main subject of the meeting, thus integrating a large community of psychologists and neuropsychologists from Brazil.

The second annual meeting of the IBNeC offered five pre-congress courses that focused on recent contributions in the area including Neuropsychiatry and Clinical Psychology, Early Stress and Mental Malfunctions, Clinical Neuropsychology, Neuropsychological Testing, and Teaching Basic Psychological Processes. This scientific event comprised 24 plenary conferences, eight discussion sessions that presented individual clinical data, and 170 poster presentations. Researchers with relevant contributions in the area including Frederic Peters (University of Montreal, Canada) and Fernando Cardenas (University of Los Andes, Bogotá, Colombia) were invited to contribute to the meeting. These combined efforts clearly demonstrated the engagement of IBNeC in promoting the improvement of high-quality teaching in a fundamental domain of psychological practice. Two homage ceremonies recognized the contributions of Professor Maria Alice de Mattos Pimenta Parente (UFRGS), who was introduced by Professor Rochele Paz Fonseca (PUCRS), and Professor João Cláudio Todorov (UnB), who was introduced by Professor Deisy das Graças de Souza (UFSCar).

At the end of the second annual meeting of the $\mathrm{IBNeC}$, Florianopolis (SC) was selected as the venue for the third annual meeting. This special issue of Psychology \& Neuroscience is a small sample of the range and quality of the rich information shared during those 3 days. This special issue also invites all who are interested in neuroscience to attend the next meeting and join the community of Brazilian researchers in neuroscience and neuropsychology to reduce the gap among research, academics, and professional practice. 
